\title{
A TEORIA DA INDEPENDÊNCIA DO BANCO CENTRAL APLICADA À REALIDADE BRASILEIRA
}

\author{
Cleydner Marques de Magalhães Maurício - Mestre em Administração pela UFAL
}

Professor de Economia da FEAC/UFAL

Widelyne Maria da Conceição- Mestranda em Economia pelo PIMES/UFPE

\begin{abstract}
RESUMO - Este artigo retrata a Teoria da Independência do Banco Central aplicada à realidade brasileira, tendo como objetivo identificar se a adoção de um Banco Central Independente beneficia a economia brasileira com vistas à retomada do crescimento e desenvolvimento do país. Por meio de uma abordagem qualitativa foi utilizado pesquisa exploratória e procedimentos técnicos relativos à investigação do trabalho. Após análise, levando-se em consideração as avaliações teóricas e empíricas de Alex Cukierman, principalmente, verificou-se que a independência do BACEN por si só não é capaz de alterar o status do país que necessita de mudanças mais profundas tanto em sua economia quanto política e até mesmo mudanças sócio-culturais.
\end{abstract}

PALAVRAS-CHAVE: Teoria da Independência do Banco Central, Autonomia, BACEN.

\section{THE THEORY OF INDEPENDENCE OF THE CENTRAL BANK APPLIED TO BRAZILIAN REALITY}

\begin{abstract}
This article shows the Central Bank's Theory of Independence applied to Brazilian reality and its objective is identify if the adoption of an Independent Central bank benefits the Brazilian economy in order to resume its growth. Through a qualitative approach, exploratory research and technical procedures, taking in consideration mainly the Cukierman's theoretical and empirical studies, we concluded that the Brazilian central bank independency by itself is not able to change the Brazilian economic condition that needs deeper changes in Brazilian economy as well as changes in its policy even socio-cultural changes.
\end{abstract}

PALAVRAS-CHAVE: Central Bank 's Theory of Independence, Autonomy; BACEN.

\section{INTRODUÇÃO}

Diante de inúmeros estudos sobre o motivo que ainda impede a evolução e desenvolvimento do Brasil, país com grande potencial econômico, não se obteve uma resposta definitiva ou algo preciso que solucionasse o "problema do subdesenvolvimento" (FURTADO, 1999, p.40).

Após as dificuldades enfrentadas nas décadas de 1980 e 1990, os anos 2000 podem ser considerados de grande alívio para a economia brasileira. Entre 2000 e 2008 o Brasil quase quadruplicou suas exportações. Já entre 2003 e 2007 o país aumentou em cinco vezes o investimento externo, fato este que deu certo fôlego interno enquanto o mundo passava por forte crise no ano seguinte.

De certa forma, apesar de no ano de 2009 o país ter enfrentado grande queda nos índices econômicos, não se pode considerar este como um ano tão ruim para o Brasil quanto foi para o resto do mundo que, com a explosão dos "papéis podres" em 2008, estava em plena crise 
mundial. Mesmo que em ritmo menor de crescimento e exportações, o governo continuou a trabalhar, agora com medidas anticíclicas e grandes expectativas para os próximos anos.

O ano de 2010 foi o de melhor desempenho do PIB brasileiro dos últimos 35 anos: um paradoxo. O governo comemorava o sucesso e estava animado para o início do mandato do próximo presidente. Entretanto, os anos seguintes podem ser considerados como um ponto de inflexão negativo para o país. 2010 foi o último ano dourado na economia brasileira, porque, a partir de então, o Brasil parou de crescer, passando a enfrentar uma descida contínua em seus índices econômicos e, consequentemente, sociais.

Com exceção do ano de 2013 que sofreu alguns altos e baixos, entre 2011 e 2014, houve uma diminuição constante do crescimento da economia em que os números chegaram a ser inferiores até mesmo quando em comparação com a década perdida (LANZANA, 2014).

O primeiro mandato de Dilma Rousseff pode ser considerado um desastre. De acordo com os economistas, o ano de 2015 foi considerado um ano perdido em que toda a situação econômica nacional foi por água a baixo. Começou com a alta do dólar próxima a $\mathrm{R} \$ 4$, inflação acima de $10 \%$ e alta taxa de desemprego que chegou a $8,9 \%$.

O ano de 2016 foi marcado por forte depressão resultante de políticas econômicas passadas, queda de produção industrial, queda nos resultados do setor de serviços e altos índices de desemprego.

Em 07 de março de 2017, para de fato consumar a problemática situação brasileira, o Instituto Brasileiro de Geografia e Estatística (IBGE) divulgou o resultado do PIB de 2016: a queda foi de $3,6 \%$ em relação a 2015 , que já havia também enfrentado um crescimento negativo de $3,8 \%$. Como já esperado, foi o pior desempenho da economia desde a década de 30, período pós-crise de 1929 e recessão mundial. Pela segunda vez na história o Brasil teve duas quedas consecutivas de crescimento.

Após a divulgação desses dados negativos, o atual Ministro da Fazenda, Henrique Meirelles, em seu discurso durante a reunião do Conselho de Desenvolvimento Econômico e Social, o "Conselhão" afirmou que "O PIB divulgado hoje se refere ao ano passado. É olhar no espelho retrovisor. [...] É o resultado de uma série de políticas que levaram a economia brasileira a enfrentar a maior crise da sua história”. (MEIRELLES, 2017, informação verbal).

A recente crise tem origem, de certa forma, a partir das dificuldades enfrentadas pelo sistema financeiro norte-americano a partir de 2008 e 2009. "Esse processo contou com a complacência dos órgãos que deveriam, teoricamente, regulamentar e fiscalizar o mercado, como agências reguladoras e os bancos centrais" (KLIASS, 2016, p. 8).

A conjunção das crises política e econômica no país resultou no impeachment da Presidente Dilma Rousseff neste mesmo ano e conseqüente assunção de seu vice-presidente, 
Michel Temer. Em consonância com o hábito brasileiro, a troca da equipe econômica foi tão inevitável quanto o próprio processo de impeachment, sendo, portanto, substituído o então Presidente do Banco Central do Brasil, Alexandre Antônio Tombini, por um economista, reconhecido e respeitado pelo mercado, Ilan Goldfajn.

A "dança das cadeiras" do Sistema Financeiro (e até mesmo político) traz à reflexão sobre qual seria a relação entre o desenvolvimento do país e a interação Governo-Banco Central.

Esse artigo delimitado pela análise da Teoria da Independência do Banco Central aplicada à realidade brasileira tem por objetivo identificar se a adoção de um Banco Central Independente beneficiará a economia brasileira com vistas à retomada do crescimento e desenvolvimento do país.

A hipótese em análise é a de que a maior independência do Banco Central do Brasil (BACEN) proporciona ao país maior desenvolvimento econômico e provável evolução do Brasil do patamar de país emergente a país desenvolvido.

Para esse artigo utilizamos a abordagem qualitativa, sendo realizada uma pesquisa exploratória com consultas bibliográficas, como livros, artigos etc.

O referencial teórico deste artigo é baseado na leitura e análise de obras relativas ao tema, tanto clássicas, quanto keynesianas, ressaltando as principais idéias e pontos analisados em cada obra.

\section{A ORIGEM DO BACEN E A TEORIA DA INDEPENDÊNCIA (IBC)}

O BACEN foi criado em 31 de dezembro de 1964 com a promulgação da Lei $n^{\circ} .4 .595$ que dava início à grande reestruturação do próprio Sistema Financeiro Nacional, motivada pela preocupação com a estabilidade monetária num contexto de alta inflação no período. Criou-se, como órgão de cúpula do sistema, em substituição ao Conselho Superior da Sumoc, o CMN, cuja composição variou bastante ao longo dos últimos anos.

A Lei no. 4.595/64 concedeu mandatos fixos ao presidente e diretores do Banco Central, sinalizando para a autonomia da instituição. Na prática, porém, a autonomia da instituição não vigorou, até que pela Lei $\mathrm{n}^{\circ}$. 6.045, de maio de 1974, os mandatos fixos foram formalmente revogados.

Desde a promulgação da Lei 4.595, buscou-se dotar o BACEN de instrumentos legais para o desempenho do papel de "banco dos bancos". Além disso, coube-lhe exercer o monopólio de emissão, nos termos do artigo 164 da Constituição da República Federativa do Brasil, e da Lei 4.595, que estabeleceu competência privativa do BACEN para emitir papelmoeda e moedas metálicas e executar os serviços do meio circulante, a supervisão do Sistema Financeiro Nacional (SFN) e executar as políticas monetárias e cambiais. 
Essa mesma Lei não definiu, no entanto, limites claros de separação na relação entre o BACEN, o Banco do Brasil (BB) e o Tesouro Nacional, o que dificultava a atuação do BACEN na condução da política monetária, cabendo-lhe inclusive a responsabilidade por contas do orçamento fiscal, como as relativas à dívida pública. Em 1985, com o objetivo de definir linhas mais claras de responsabilidade na atuação do BACEN, foi promovida a reorganização financeira governamental com a separação das contas-movimento e das funções do BACEN, BB e Tesouro Nacional.

Em 1986 foi extinta a conta movimento que marcava o relacionamento entre BACEN e $\mathrm{BB}$, e a transferência de recursos do BACEN ao BB passou a ser claramente identificada nos orçamentos das duas instituições. Eliminaram-se, dessa forma, os suprimentos automáticos que prejudicavam a atuação do BACEN no controle monetário e contribuíam para a aceleração da inflação observada naquela época.

Até o fim da conta-movimento, o Banco do Brasil não tinha limites de caixa para suas operações, ao contrário dos demais bancos comerciais, pois essa conta garantia suas eventuais necessidades de recursos. Esta reorganização se estendeu até 1988, quando as funções de autoridade monetária foram transferidas progressivamente do Banco do Brasil para o Banco Central, enquanto as atividades atípicas exercidas por este último, como as relacionadas ao fomento e à administração da dívida pública federal, foram transferidas para o Tesouro Nacional.

Outro avanço importante na definição exclusiva de atuação do BACEN como autoridade monetária foi conquistado pela Constituição Federal de 1988, proibindo o BACEN de conceder direta ou indiretamente empréstimos ao Tesouro Nacional. Posteriormente, o artigo 34 da Lei de Responsabilidade Fiscal (Lei Complementar n. 101/2000) impediu a emissão de títulos da dívida pública pelo BACEN para fins de política monetária, a partir de maio de 2002, reforçando mais ainda a separação entre autoridade fiscal e autoridade monetária.

A evolução do SFN e, consequientemente surgimento do próprio BACEN, vêm para corroborar os estudos de Aglietta (1991) e Goodhart (1985) no que tange à emergência dos Bancos Centrais motivada pelo próprio desenvolvimento da economia monetária de um país.

O significado do termo independência tem aparecido na maior parte da literatura como a capacidade do Banco Central em não ceder frente às forças políticas para monetizar grandes déficits orçamentários. Ou seja, há a necessidade de independência institucional em relação aos poderes Executivo e Legislativo.

Sendo assim, a presença de um Banco Central Independente (BCI) em uma economia, teria, a priori, uma dupla vantagem: acabaria com as pressões advindas da esfera política (fonte do viés inflacionário), e faria com que o BC pudesse se concentrar em sua meta natural: a busca da estabilidade de preços.

\begin{tabular}{lllll}
\hline REVISTA ECONOMIA POLÍTICA DO DESENVOLVIMENTO & Maceió - AL & V.4 N.6. & DEZEMBRO/2017 & P.64-79 Página-67
\end{tabular}


A Teoria da Independência dos Bancos Centrais cresceu após uma confluência de diversos fatores. Um deles foi a onda inflacionária nos países desenvolvidos na década de 1970. Subjacente a isto, está o aumento da procura pela estabilidade de preços.

Conforme analisado, existem Bancos Centrais que possuem mais de um objetivo previsto em seu estatuto e, por diversas vezes, estes objetivos podem ser incompatíveis entre si.

Após a estagflação dos anos 70 e desempenho econômico adverso de alguns países de inflação elevada na América Latina e em outras regiões, a postura convencional relativa à inflação e ao crescimento real mudou. De acordo com Carvalho (2011), se nos anos 60 se aceitava a idéia, na linha do dogma keynesiano, de que certa inflação favorecia o crescimento, nos anos 80 e 90 predominou a opinião de que a inflação e as incertezas a ela associadas retardam o crescimento.

O bom desempenho de alguns países de inflação baixa, como a Alemanha e o Japão, reforçaram esse ponto de vista. O rápido crescimento e a internacionalização dos mercados de capitais aumentaram a importância da estabilidade de preços na medida em que os governos e os investidores privados procuraram melhorar seu acesso aos mercados financeiros mundiais em expansão. O colapso de outras instituições desenvolvidas para salvaguardar a estabilidade nominal, como o Sistema Monetário Europeu (SME) e o Sistema de Bretton Woods, intensificou a procura por instituições alternativas.

O bom desempenho passado do altamente independente Bundesbank demonstrou que a IBC pode funcionar como um dispositivo efetivo de garantia da estabilidade nominal. Adicionalmente, a aceitação do Tratado de Maastricht pela Comunidade Econômica Européia (CEE) implica que, para se amoldarem ao tratado, muitos países da comunidade têm de fortalecer a independência de seus Bancos Centrais como condição inicial para o ingresso na União Monetária Européia (UME).

O fato de essa cláusula ter sido introduzida antes das demais no tratado tem a ver com o bom desempenho do Bundesbank e com a posição central da Alemanha na comunidade.

Após o êxito recente na estabilização da inflação, sobretudo na América Latina, os formuladores de políticas estão buscando mecanismos institucionais capazes de reduzir a probabilidade de inflação alta e persistente no futuro. Dada a experiência recente, o fortalecimento da IBC é o caminho natural para a consecução desse objetivo.

O fato de muitos desses novos Bancos Centrais serem bastante independentes é motivado pelos exemplos recentes das economias industrializadas, afirmou Sicsú (1996), o que sugerem que inflação e independência legal se relacionam negativamente e que independência e crescimento ou se relacionam positivamente ou não se relacionam. 
Para Sicsú (1996), o argumento-chave de defesa da tese da IBC é a existência desta correlação negativa entre o grau de independência das autoridades monetárias de diversos países e a taxa de inflação verificada respectivamente em cada economia.

Gráfico 1 - Grau de Independência do Banco Central de 14 países x taxas de inflação no período 1955-1988

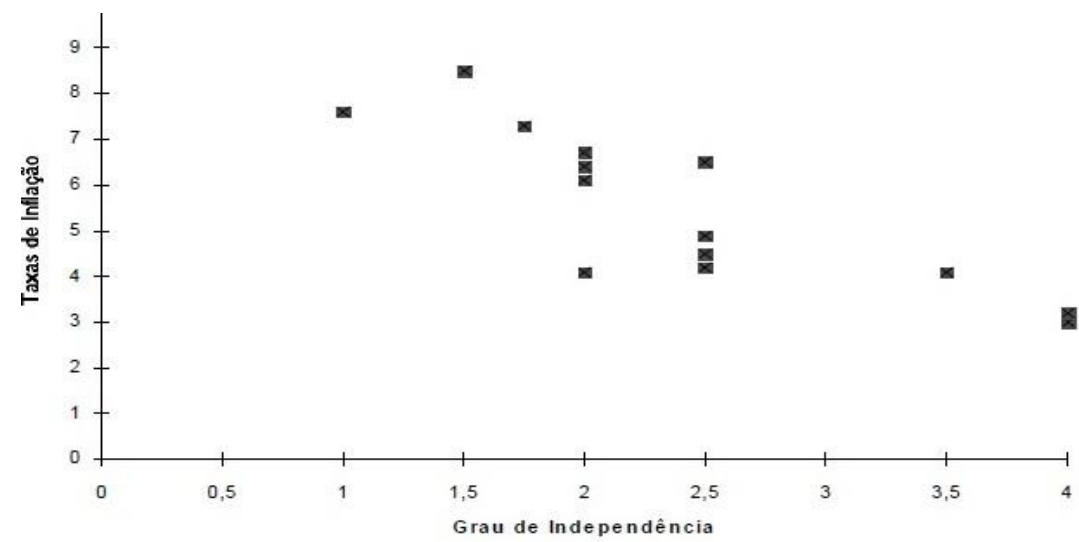

Fonte: Alesina \& Summers (1993)

Alesina \& Summers (1993) relacionaram o grau de independência dos Bancos Centrais de 14 países com a média das taxas de inflação do período 1955-88 destas economias. Como indica o Gráfico 2 construído pelos autores, existe um alto grau de correlação entre as variáveis analisadas, aproximadamente, 0,84 (negativo).

A teoria moderna sobre credibilidade atribui a existência do viés inflacionário à inconsistência dinâmica da política monetária no modelo expectacional da curva de Phillips de determinação do produto ou do imposto inflacionário.

A IBC também surge a partir da identificação deste viés inflacionário e visa a construir a credibilidade da política monetária, reduzindo ou até mesmo eliminando o viés inflacionário. Ao mesmo tempo, objetiva preservar a flexibilidade dessa política para que possa estabilizar a produção e a taxa de desemprego em torno das respectivas tendências de longo prazo.

Nesse sentido, um BCI seria capaz de comprometer-se com uma inflação baixa sem sofrer pressões do governo para o financiamento de déficits. Ou seja, um BCI seria capaz - de acordo com seus defensores - de estabilizar o nível de preços da economia e ainda disciplinar os gastos do governo.

Ainda de acordo com a IBC, diversos efeitos sobre a economia podem ser percebidos após sua implementação. O mais propalado resultado de um BCI refere-se ao fato de que a implementação de uma autoridade monetária independente seria capaz de garantir uma taxa de inflação menor e mais estável para o país que adotasse essa estrutura. 
Apesar de este resultado ser a evidência empírica mais referida pelos defensores de um BCI, deve-se ressaltar que tais evidências não indicam que este resultado seja válido para o caso dos países emergentes.

Cukierman (1994) destaca o fato de que a experiência de países que convivem com elevada inflação tem demonstrado que a conquista da estabilidade tem sido obtida via desenvolvimento. Portanto, tal objetivo não pode ser alcançado somente pela delegação de autoridade para o BC, uma vez que a discussão sobre Bancos Centrais Independentes não está atrelada apenas ao aspecto econômico, mas também ao político.

$\mathrm{O}$ que pode ser ponderado é que delegar autoridade para o $\mathrm{BC}$, de forma a tornar seu compromisso com a inflação crível pelo público, constitui-se em um instrumento que pode funcionar como efeito preventivo na repetição de episódios que favoreçam ao incremento da inflação.

Outra importante observação para Bancos Centrais Independentes refere-se à possível mudança de comportamento da autoridade monetária quanto à determinação da taxa de juros. As evidências empíricas, presentes na literatura, mostram que não há uma clara relação que possa ser encontrada entre a independência e a média das taxas de juros reais. Esta é uma constatação importante porque traz implicações significativas para avaliar os impactos de um BCI sobre o crescimento econômico.

Boa parte dos economistas tem sustentado a hipótese de que a inflação é prejudicial para o crescimento econômico, uma vez que o efeito direto é um aumento do nível de incerteza.

Como é admitido que um BCI seja capaz de garantir uma menor variabilidade da inflação, é esperado, ao menos no plano teórico, que com a redução da incerteza sobre a inflação os agentes possam aumentar a capacidade de planejamento. A conseqüência desta observação é que haveria um aumento do investimento da economia acarretando um aumento da demanda agregada.

Em outras palavras, sob esta interpretação, um BCI poderia ter um efeito positivo para o crescimento econômico.

\section{BREVES CONSIDERAÇÕES TEÓRICAS DA IBC}

A teoria da Independência do Banco Central tem como pilares teóricos a economia novoclássica e apóia-se também nas discussões estabelecidas pelo trinômio credibilidade-reputaçãodelegação, cuja questão central é a tentativa de se eliminar a possibilidade de implementação de políticas monetárias consideradas dinamicamente inconsistentes.

Cukierman, Webb, Neyapti (1992) esclareceram que a independência de um Banco Central não significa somente autonomia para realizar políticas monetárias sem a 
interferência do governo central, significa, acima de tudo, independência para perseguir o objetivo da estabilidade de preços; mesmo que esta busca represente sacrificar outros objetivos que podem ser mais importantes para as autoridades políticas.

Os proponentes da tese da IBC têm argumentado que um BC independente deve assumir a tarefa estatutária única de guardião da estabilidade do poder de compra da moeda. Goodhart (1994) afirmou que se a política monetária possui mais de um objetivo e estes caracterizam um processo de escolha onde emerge um trade-off (inflação e desemprego, por exemplo), então, a decisão sobre os rumos monetários será certamente uma decisão política - tomada fora do BC. Logo, nestes casos, o BC tende a ser mais subserviente, portanto, menos autônomo.

"Maior autonomia é mais provável que ocorra quando os Bancos Centrais buscam alcançar um único resultado macro, tal como a manutenção do padrão ouro até 1914, ou a estabilidade dos preços hoje". (GOODHART, 1994, p. 1427).

Goodhart (1994) estabelece ainda outro conteúdo para o termo inserindo-o na tese da IBC. Explica que, uma vez perdida a força por parte do governo de controlar a política monetária, a política fiscal pode se tornar mais disciplinada.

Apesar de a IBC ter como arcabouço teórico o estilo novo-clássico, Milton Friedman, o principal expoente do monetarismo, opõe-se radicalmente à Teoria de Independência do Banco Central. Friedman (1968) avalia que é perigoso concentrar a alguns indivíduos a liberdade para acionar sem qualquer restrição instrumentos tão poderosos quanto os instrumentos de intervenção monetária.

Muitos estudos foram realizados com o objetivo de mensurar os reais efeitos da IBC na economia. Os primeiros resultados encontrados indicaram relação estatisticamente relevante e inversamente proporcional entre grau de IBC e inflação. Estes resultados, juntamente com os fundamentos teóricos desenvolvidos, deram impulso à teoria. Entretanto, as pesquisas posteriores não foram mais tão satisfatórias. A mensuração da IBC foi questionada e a relação entre IBC e inflação, reinterpretada, pois os ganhos de credibilidade esperados com a adoção desse arranjo institucional não foram confirmados.

Dois trabalhos buscaram analisar separadamente a capacidade da autonomia instrumental e a de objetivos para explicar a inflação. Debelle \& Fischer (1995), como base nos índices de Grilli, Masciandaro \& Tabellini (1991), concluem que a autonomia de instrumentos é relevante, enquanto a autonomia de objetivos é importante apenas quando reduzida ao quesito "presença da estabilidade de preços entre os objetivos do Banco Central".

De Haan (1995) partiu dos índices de Cukierman, Webb \& Neyapti (1992) e chegou apenas à relevância da autonomia instrumental, entendida basicamente como o segundo grupo 
de variáveis empregado por estes autores: o Banco Central toma a decisão final sobre a política monetária e há procedimentos para a solução de conflitos com o governo.

A conclusão de Cukierman, Webb \& Neyapti (1992) relacionada aos países em desenvolvimento é de que, diferentemente dos países desenvolvidos, não se constata relação inversa significativa entre inflação e independência legal, mas, sim, relação direta entre inflação e autonomia de fato, medida pela rotatividade do presidente do Banco Central.

A pouca importância da autonomia legal é interpretada como decorrente da baixa aderência da prática às normas, comparativamente ao verificado em países desenvolvidos.

Gutiérrez (2003) analisa os países da América Latina e do Caribe e conclui que a relação inversa entre IBC e inflação pode ser encontrada quando se utiliza a constituição em vez das leis para verificar a autonomia legal dos Bancos Centrais.

\section{A AUTONOMIA DO BANCO CENTRAL DO BRASIL}

De acordo com Costa e Silva (2014), o termo Independência Central do Brasil não é de correta utilização, pois independência denota uma isenção total de prestação de contas do BACEN ao Governo brasileiro ou a órgãos governamentais, como, por exemplo, o Conselho Monetário Nacional (CMN).

$\mathrm{Na}$ língua portuguesa, o termo "Independência" por definição pura poderia ser encarado como uma espécie de quarto poder no país. Portanto, o termo autonomia seria mais coerente para a finalidade que se pretende ter o BACEN.

Por esta razão, ao se tratar do BACEN, o termo "independência", como normalmente aparece nos textos internacionais (independence) será utilizado como sinônimo da referida "autonomia" citada por Costa e Silva (2014), autonomia esta relacionada à escolha pela autoridade monetária dos objetivos, metas e instrumentos.

Na década de noventa, o tema da autonomia do BACEN ganhou relevo possivelmente como reflexo do entusiasmo internacional e das dificuldades de o país livrar-se do descontrole inflacionário. Por conseqüência, o tema esteve sempre presente nas discussões sobre a pendente regulamentação do sistema financeiro, prevista no art. 192 da Constituição Federal.

O mais recente plano de estabilização monetária brasileiro foi o plano Real, implantado no governo de Fernando Henrique Cardoso e sua equipe econômica.

Novelli (1998) afirma que é possível observar o debate sobre autonomia do Banco Central em diferentes períodos da história, entretanto, foi no governo de Fernando Henrique Cardoso que essa instituição sofreu diversas alterações relevantes. 
Segundo Novelli (1998), a autonomia do Banco Central no Brasil durante o governo FHC não foi construída juridicamente, ela limitou-se à liberação operacional do BACEN, uma não intervenção realizada por opção política. Além disso, delimitou a ação do Banco Central ao que o autor chamou de "funções clássicas", em especial a manutenção da estabilidade do poder de compra da moeda nacional. Nesse sentido, o Banco Central passou a possuir grande margem de autonomia para definir a política de juros do governo por meio do controle da Taxa Selic, mesmo não podendo se opor diretamente à política econômica mais geral.

Nos últimos anos, mais especificamente em 2014, o tema ressurgiu com força nas propostas de governo dos candidatos à eleição para Presidente da República Marina Silva e Aécio Neves. Amos candidatos demonstraram a intenção de mudar a relação do Governo com a autarquia. Adicionalmente, o tema da autonomia do BACEN surgiu como proposta destinada a aperfeiçoar o regime de metas para a inflação, adotada em junho de 1999, visando substituir a âncora cambial em vigor desde 1994.

Outro fator que deve contribuir para a resistência à autonomia do BACEN é o fato de que a proposta não vem sendo defendida com profundidade. Nos textos que abordam a política monetária no Brasil, a autonomia costuma ser lembrada como forma de aprimorar a credibilidade do regime de metas para a inflação, mas quase nunca é o elemento central da análise.

Alguns trabalhos dedicam mais atenção ao tema, como Maziero \& Werlang (2004) e Sabbán, Rozada \& Powell (2003). Em ambos os casos, entretanto, as dificuldades estão presentes. O primeiro trabalho não levou em conta os resultados empíricos desfavoráveis à autonomia do banco central encontrados pela literatura relevante. $\mathrm{O}$ segundo não apresenta elementos suficientes para concluir que o pior desempenho do Brasil e do México, relativamente a outros países que adotam o regime de metas para a inflação, se deva ao menor grau de autonomia dos respectivos Bancos Centrais.

Fraga, Goldfajn \& Minella (2003), contrariamente a Sabbán, Rozada \& Powell (2003), destacam os grandes desafios à gestão do regime de metas para a inflação nas economias emergentes, como elevada inflação inicial, reduzida credibilidade derivada do histórico, alto grau de inércia inflacionária, maior intensidade dos choques externos e a presença de dominância fiscal.

Fraga, Goldfajn \& Minella (2003) não incluem a falta de autonomia do BACEN entre os desafios e, por consequiência, ao tratarem dos elementos necessários para enfrentar estes desafios, não citam a concessão de autonomia. A recomendação central é a gestão da política monetária com suficiente flexibilidade, recorrendo-se à comunicação e à transparência para não prejudicar a credibilidade.

Henrique Meirelles, atual Ministro da Fazenda, é um ferrenho defensor da Independência formal do Banco Central. Meirelles foi presidente do BACEN e, neste período, foi forte defensor REVISTA ECONOMIA POLÍTICA DO DESENVOLVIMENTO $\quad$ Maceió - AL $\quad$ V.4 N.6. $\quad$ DEZEMBRO/2017 P.64-79 Página-73 
da autonomia do Banco Central. Para o atual Ministro, a autonomia é o melhor caminho para o fortalecimento da autoridade monetária. Em 2012, ao participar de um seminário intitulado "Guardiões da Estabilidade", Meirelles afirmou que a autonomia do Banco Central do Brasil tratava-se de "um assunto da maior importância", que estava "sendo pouco visto".

Há atualmente projeto de lei em votação no Senado, cujo texto de autoria do senador Renan Calheiros, prevê mandatos fixos e alternados de seis anos para a diretoria, desatrelando as trocas do período eleitoral. "Haveria mecanismos que dificultariam as substituições políticas, sem uma causa específica”. (LOYOLA, 2016 - Em entrevista para o site Isto é Dinheiro).

A maioria dos especialistas concorda com a visão de Meirelles de que, por definição, os Bancos Centrais com maior grau de autonomia têm mais credibilidade e, consequentemente, precisam de um esforço monetário menor para atingir os seus objetivos. O México, por exemplo, é sempre citado por Meirelles como um modelo exitoso de blindagem às diversas forças políticas.

Segundo Schwartsman (2014), o Banco Central brasileiro com o atual modelo de operação fica atrás de outros Bancos Centrais latino-americanos como os do Chile, Peru, Colômbia e México.

Para Júlio Sena (2016), o aumento da autonomia do BACEN daria uma boa sinalização ao mercado. "A chance de aprovar é grande porque, atualmente, não tem muita gente lutando contra um Banco Central independente" (SENA, 2016, Em entrevista para o site Isto é Dinheiro).

Desde a criação do BACEN, em 1964, o grau de autonomia permitido pelo arranjo escolhido sempre foi muito reduzido, exceção feita aos anos iniciais, no governo Castelo Branco (1964-67). As características essenciais do arranjo foram sendo conformadas pelos governos seguintes, de forma a garantir-lhes a maioria no Conselho Monetário Nacional $(\mathrm{CMN})$ e o direito de indicar os dirigentes do BACEN, sem mandatos fixos.

De fato, no trabalho de Cukierman, Webb \& Neyapti (1992) que, como visto anteriormente, desenvolveu medidas para o grau de IBC, o BACEN aparece como um dos Bancos Centrais menos autônomos da década de oitenta, dentre os países incluídos na amostra. No caso da medida de autonomia legal, somente nove entre 72 países possuíam banco menos autônomo.

Entre os 51 países não desenvolvidos, os autores calculam o índice de rotatividade do presidente do Banco Central. Supõem que quanto maior a rotatividade, menor a autonomia de fato. O índice do Brasil só é inferior ao da Argentina. O indicador mostra que a troca do dirigente máximo do BACEN se deu a cada um ano e três meses, durante a década de oitenta.

É oportuno destacar algumas mudanças a partir de meados da década de oitenta que, embora não tenham eliminado a subordinação do Banco Central do Brasil ao governo, 
representaram avanços em termos da autonomia instrumental da Autarquia, resultado constatado por Souza \& Castro (1995).

Vale destacar a retirada das operações fiscais do BACEN, incluindo o fim da chamada "conta movimento", que conferia ao Banco do Brasil poder para emitir moeda; o art. 164 da Constituição Federal, que, no parágrafo primeiro, vedou expressamente o financiamento ao governo; e, posteriormente, a solução dada aos bancos estaduais, fonte de periódicas crises monetárias.

No contexto do regime de metas para a inflação, adotado em 1999, a versão instrumental da IBC ganhou importância como meio para elevar a credibilidade do regime. A autonomia instrumental normalmente inclui as seguintes providências:

a) estabilidade de preços como objetivo primordial;

b) mandatos fixos e/ou longos para os dirigentes.

No contexto do regime de metas para a inflação, a proposta de autonomia sugerida é do tipo instrumental, também seguindo o exemplo de outros países. O governo define a meta e o BACEN utiliza os instrumentos para alcançá-la. A intenção de introduzir a autonomia instrumental deve ter impulsionado a aprovação da Emenda Constitucional $\mathrm{n}^{\circ}$. 40, de 29 de maio de 2003, que alterou o art. 192, tendo em vista possibilitar a regulamentação "fatiada" do sistema financeiro.

A opção pela autonomia do BACEN após a redução da inflação a níveis civilizados, ainda que acima do desejável, parece reproduzir a experiência internacional na qual a autonomia surge para consolidar os avanços mais expressivos, além de propiciar novos ganhos no campo do controle da inflação. Entretanto, no Brasil, a resistência à autonomia é ainda muito grande.

Talvez haja receio quanto ao aumento da influência de certos interesses no BACEN e/ou quanto ao excessivo aumento do peso da inflação na definição da política monetária, com reflexos sobre a produção e a taxa de desemprego. Talvez se acredite que a autonomia seja pouco relevante frente aos desafios ainda presentes para o controle da inflação no Brasil.

Esses argumentos não são irrelevantes. Como visto anteriormente, a imprecisão de objetivos, a formatação inadequada da autonomia, a convivência de múltiplas atribuições, a falta de suporte político ou a presença de fatores fortemente restritivos à gestão da política monetária podem fazer com que a autonomia gere resultados ruins ou que seja inoperante.

Destaque-se ainda que, conforme visto anteriormente, as pesquisas empíricas, de forma geral, não permitem confirmar com razoável grau de certeza que os países que optam por bancos centrais mais autônomos apresentam ou não melhor desempenho econômico.

As partes que seguem comentam os trabalhos disponíveis em defesa da autonomia do BACEN, descrevem o regime de metas para a inflação no Brasil, na qual se pretende inserir a 
autonomia instrumental do Banco Central, propõem uma forma de aumentar a autonomia do BACEN, levando-se em conta os possíveis riscos envolvidos e o equilíbrio ideal entre credibilidade e flexibilidade da política monetária, abordam as demais atribuições do BACEN e, por fim, tratam dos principais obstáculos à gestão da política monetária, entre os quais a possível presença da dominância fiscal.

\title{
ARGUMENTOS CONTRÁRIOS A MAIOR AUTONOMIA DO BACEN.
}

Por se tratar de um assunto bastante delicado, principalmente num país como o Brasil cujas raízes históricas influenciam toda a trajetória do país, existem inúmeros autores que argumentam contra a maior autonomia do Banco central. Dentre estes autores, Kliass (2014) afirma que:

\begin{abstract}
Com o argumento malandro de que o governo pode influenciar "politicamente" na definição da política monetária, o financismo agora pede um pacote completo: deseja a independência do BC. Voltam com a argumentação surrada e mal lavada de que é importante haver "técnicos" não suscetíveis de serem influenciados por quem estiver ocupando o Palácio do Planalto. Mas o presidente do BC deve ser independente de quem, cara pálida? O sonho de consumo da banca é um quadro de dirigentes no comando da autarquia vinculada ao Ministério da Fazenda que não respondam a ninguém. Ou melhor, que atendam tão somente aos interesses das instituições que deveriam controlar. (KLIASS, 2014, p. 14)
\end{abstract}

O "financismo" citado por Kliass relaciona-se ao fato de que o Brasil, assim como a maioria dos países no mundo tem cedido ao capital estrangeiro e cada vez mais dissociado a imagem do Estado como gerenciador e regulador do desenvolvimento econômico e social do país.

Kliass (2014) realça que a abertura crescente do país e a gerência do BACEN por presidentes ligados ao mercado financeiro podem ser altamente perigosas, pois, desregulamentam a economia concedendo todo tipo de facilidades ao mercado financeiro e aprofundam a hegemonia do capital financeiro no sistema econômico e social brasileiro. Fato este que ele afirma que é comprovado pelo período em que a autoridade monetária mais autônoma, iniciado no ano de 2003 através do governo Lula com o então presidente do BACEN Henrique Meirelles, governou mais para os bancos e menos para o conjunto da sociedade. Kliass (2014) afirma ainda que, neste período, as taxas de juros foram estratosféricas e foram definidas pelo COPOM sem nenhuma prestação de contas, nem ao governo e menos ainda à sociedade.

No ano de 2014, em palestra na sede do Banco Central da Índia, o economista americano Joseph Stiglitz, agraciado com Prêmio Nobel de Economia em 2001 e economistachefe do Banco Mundial entre 1997 e 2000, afirmou que a discussão sobre a independência dos Bancos Centrais é superestimada.

A crise mostrou que um dos princípios centrais defendidos pelos banqueiros do CentroOeste (Europa e Estados Unidos) é o desejo de independência do Banco Central [...] Mas na melhor das hipóteses, essa posição é questionável. Na crise, os países com 
Bancos Centrais menos independentes como China, Índia e Brasil fizeram muito, mas muito melhor mesmo do que os países com Bancos Centrais mais independentes, caso da Europa e dos Estados Unidos. (STIGLITZ, 2014, informação verbal).

\section{CONCLUSÃO}

A fim de analisar a hipótese desta pesquisa que consiste em verificar se a maior independência do Banco Central do Brasil proporcionaria ao país maior desenvolvimento econômico e provável evolução do Brasil do patamar de país emergente a país desenvolvido, foi necessário apresentar a origem e evolução do BACEN, bem como as principais correntes que fundamentam a Teoria da Independência do Banco Central.

Como já é do conhecimento acadêmico, o Banco Central se utiliza da política monetária e seus instrumentos para assegurar a saúde da economia de um país através da estabilidade de preços no que tange à moeda e suas funções.

As duas das principais correntes que discorrem a respeito da política monetária: a teoria clássica que, no geral, afirma que a política monetária não é capaz de alterar o nível de produção da economia e que a elevação de moeda em circulação é sempre acompanhada de uma elevação no nível geral de preços e, em contraposição, a teoria keynesiana cujos estudos vêm para afirmar que a política monetária é sim capaz de alterar o nível de emprego, além de dar importância à moeda, tornando-a endógena ao sistema.

A credibilidade da política monetária e o viés inflacionário estimularam o surgimento da Teoria da Independência do Banco Central e, mais especificamente, a independência ou, no caso brasileiro, a autonomia do BACEN.

O propósito deste artigo foi não só relatar, mas analisar os aspectos que favoreçam a Teoria da Independência aplicada à realidade do Brasil que, apesar de ter a inflação relativamente sob controle em se comparando aos períodos anteriores, o aumento do nível geral de preços no Brasil é e sempre será uma preocupação que assombra os governantes a cada mandato, pois a era hiperinflacionária que o país sofreu deixou marcas que nunca serão apagadas.

$\mathrm{Na}$ realidade, todas as economias do mundo se preocupam, em maior ou menor grau, com a elevação do nível de preços da economia, sendo este, portanto, majoritariamente o principal objetivo, quando não único, dos Bancos Centrais de cada país. Entretanto, se, por definição, o objetivo do Banco Central permeia o bem estar da sociedade, não há como dissociá-lo do ideal de desenvolvimento de um país.

De acordo com a teoria que fundamentou o surgimento da IBC, o Banco Central deve envidar esforços para perseguir seu único objetivo que é o da estabilidade de preços. Além disso, a política 
monetária deve se basear em atitudes de credibilidade com o correto uso de seus instrumentos macroeconômicos sendo cada vez mais dissociados do governo para o sucesso das metas do BC.

A despeito do argumento acima se mostrar razoável, as evidências empíricas não dão suporte à idéia de que poderia haver um aumento do crescimento econômico em virtude de uma maior independência do Banco Central. Um elemento que pode justificar o porquê de não haver uma relação clara entre o crescimento e a IBC advém do fato de que, por um lado, uma maior estabilidade da economia poderia realmente incentivar o investimento privado, mas por outro, a IBC poderia reduzir o papel empreendedor do Estado em atividades que a iniciativa privada não tem interesse e que são de fundamental importância para a sociedade.

Outro ponto a ser discutido com maior engajamento é o fato de que os adeptos à IBC acreditam que o Banco Central pode ser subserviente ao poder executivo e, por muitas vezes, tomar medidas que elevem o nível de preços (através do aumento do crédito e base monetária) para satisfazer interesses políticos.

Quanto ao caráter antidemocrático da IBC, a estabilidade monetária torna-se assim um objetivo social comum, e o sucesso do Banco Central na criação e manutenção dessa estabilidade confere a esse ator social legitimidade, não sendo, portanto, um processo político antidemocrático.

É importante notar que existem obstáculos mais complexos que a falta de autonomia do BACEN para se controlar definitivamente a inflação no Brasil e o desenvolvimento do país, a exemplo da fragilidade fiscal e externa do país.

Conforme indicam as pesquisas empíricas, a autonomia não apresenta resultados na ausência de suporte político às políticas e instituições requeridas para alcançar níveis apropriados de inflação. Outro possível canal de participação democrática é a usual previsão de que o Banco Central autônomo preste contas ao governo.

Uma maneira de aperfeiçoar a atuação do BACEN seria aumentar a qualidade do próprio CMN, com maior representação de vários segmentos da sociedade.

A conclusão de Cukierman, Webb \& Neyapti (1992) relacionada aos países em desenvolvimento é a peça-chave para por em cheque a hipótese inicial deste trabalho, pois, diferentemente dos países desenvolvidos, não se constata relação inversa significativa entre inflação e independência legal, mas, sim, relação direta entre inflação e autonomia de fato, medida pela rotatividade do presidente do Banco Central, pois, na realidade, a ausência de autonomia legal é interpretada como decorrente da baixa aderência da prática às normas, comparativamente ao verificado em países desenvolvidos.

As leis brasileiras, apesar de serem bastante evoluídas quanto aos seus fundamentos, ainda encontram barreiras para serem totalmente difundidas. Um dos obstáculos mais fortes é a 
presença ainda de um formalismo enraizado na cultura da sociedade que a impede de avançar em quesitos sociais e econômicos.

Por fim, um dos principais aspectos para a evolução do Brasil de país emergente a país desenvolvido, consiste na construção da sua própria identidade, pois, desde que o Brasil foi constituído como nação, a sociedade foi treinada a copiar o que é estrangeiro, como se houvesse paridade de condições para absorvermos tudo o que se cria lá fora. $\mathrm{O}$ que se faz necessário compreender, tanto pelo cidadão comum quanto pelo responsável em formular, analisar e executar as políticas é que nem sempre o que foi sucesso em outra economia, será sucesso no país.

\section{REFERÊNCIAS}

ALESINA, A. \& SUMMERS, L. Central Bank Independence and Macroeconomic Performance: Some Comparative Evidence. .NET, mai. 1993. Journal of Money, Credit and Banking. Disponível em: < http://www.people.fas.harvard.edu/ iversen/PDFfiles/AlesinaSummers1993.pdf>. Acesso em: 10 mar 2017.

BANCO CENTRAL DO BRASIL. Acesso à Informação do BACEN. .NET, Brasília. Disponível em <http://www.bcb.gov.br/pt-br/\#!/n/LAIINSTITUCIONAL〉. Acesso em: 18 abr. 2017.

BANCO CENTRAL DO BRASIL. História do BACEN. .NET, Brasília. Disponível em 〈http://www.bcb.gov.br/pre/Historia/HistoriaBC/historia_BC.asp>. Acesso em: 18 abr. 2017.

CUKIERMAN, A., WEBB, S., NEYAPTI, B. Measuring the Independence of Central Banks and its Effects on Policy Outcomes. .NET, set. 1992. World Bank Economic Review, vol.6. Disponível em: < http://documents.worldbank.org/curated/en/797831468739529187/pdf/multipage.pdf $>$. Acesso em: 10 mar. 2017.

FRAGA, A. GOLDFAJN, I. MINELlA, A. Inflation Targeting in Emerging Market Economies. (Working Paper). Distrito Federal, Jun, 2003

FURTADO, C. O Capitalismo Global. $1^{a}$ ed. São Paulo: Paz e Terra, 1999.

LANZANA, A. Desempenho recente e cenários para 2015. . NET. São Paulo, dez 2014. Disponível em: $\langle$ http://simefre.org.br/wp-content/uploads/data/Apresentacao_Antonio_Lanzana_2014.pdf〉. Acesso em 22 mai. 2017.

SICSÚ, J. et al. Economia Monetária e Financeira. 3 ed. São Paulo: Elsevier-Campus, 2015. 